\title{
Are we Clean Enough? A Cross Sectional Study Conducted among General Dental Practitioners and Consultants of Karachi
}

\author{
Mehwash Kashif, Muhammad Abdullah Kamran, Tahera Ayub, Syed Sheeraz Hussain, \\ Muhammad Irfan Khan
}

\begin{abstract}
OBJECTIVE: To assess the connection between dentist qualification and adequacy of sterilization and to determine practices of dentist against Infection control.

METHODOLOGY: This cross-sectional study was conducted from January to June 2018. General dental practitioners and consultants with minimum clinical practice period of one or more than one year were included in the study. The exclusion criterion included general dental practitioners and consultants who did not give consent for study. A questionnaire including basic demographic data, personal protection and cross infection control measures, instrument sterilization and operatory disinfection from the General Dental Practitioner Surgeons and consultants. Total 89 clinicians were asked for their practice of sterilization and disinfection. Data was entered and analyzed on SPSS version 13.

RESULTS: According to the results mean age was $31.80 \pm 9.27$ years. Results showed that the GDPs were $57.8 \%$ and consultants were $\mathbf{4 2 . 2} \%$. Males were $\mathbf{4 6 . 7 \%}$ and females were $53.93 \%$. Mean working experience was 7.80 years and number of practicing hours per day were 6.20. Association between dentist's qualification (general dental practitioners and consultants) and different methods of sterilization were evaluated which shows significant $p$-value i.e. $<0.05$. The variables with significant $p$-value were disinfecting operatory at the end of the day i.e. 0.013 and biological sporing test i.e. 0.0175 . The practices of dentist against Infection control were also assessed.

CONCLUSION: It was concluded that the connection between dentist qualification and adequacy of sterilization in some aspects was significant, those having higher qualifications than simple graduates were doing daily and prompt sterilization.

KEYWORDS: Dentists, Sterilization, Disinfection, Clean, Consultants
\end{abstract}

This article may be cited as: Kashif M, Kamran MA, Ayub T, Hussain SS, Khan MI. Are we Clean Enough? A Cross Sectional Study Conducted among General Dental Practitioners and Consultants of Karachi. J Liaquat Uni Med Health Sci. 2020;19(02):128-32. doi: 10.22442/jlumhs.201920675

\section{INTRODUCTION}

Health care associated infections have always been an important public and medical issue worldwide. Cross infection has been defined as the transmission of infectious agents among patients and medical staff with in clinical environment ${ }^{1}$. New infectious diseases have been found at a rate of one disease per year over the past 22 years. Some of these diseases remain locally contained but others spread over large areas sometimes resulting in worldwide pandemics ${ }^{2}$. Transmission may result from person to person contact or via contaminated objects and requires a source of infection. In dentistry, the source of infectious diseases can be those who are in the prodromal stage of certain infections and healthy carriers of pathogens ${ }^{3}$.

Health care professionals are the most susceptible community exposed to these hazardous infections. Among health care workers (HCWs), professionals' dentist and dental personnel are the highest prone population. The direct exposure of body fluids i.e. blood and saliva makes them vulnerable to these infections. It has been estimated by WHO that total approximately 35 million health care workers globally have percutaneous exposure to infections ${ }^{4}$. Globally professional contact comprises for $2.5 \%$ of HIV cases and $40 \%$ of Hepatitis B and C cases among HCW $\mathrm{H}^{5}$. every year as a result of professional contact, an expected 66,000 Hepatitis B, 16,000 Hepatitis $C$ and up-to 1,000 HIV infections happen amongst $\mathrm{HCWs}^{6}$. In a study conducted in Shiraz, revealed that many almost $80 \%$ of the clinicians and health care workers were exposed to blood or body fluids of the patients ${ }^{7}$. In Pakistan, it has been reported that $93.8 \%$ of the dentists were exposed to occupational hazards during their clinical practice ${ }^{8}$.

Various infection control practices offer prompt sterilization. It involves use of personal protective barriers e.g. Gloves, masks and eyewear, vaccination against Hepatitis B, Past medical history of patients, use of sterilized instruments, disinfection of operatory at the end of the day and disinfection of operatory at the end of the day.

Monitoring of currently used system of sterilization is also very important. Different methods had been employed regarding this. The most effective method is 
the use of biological strips which designates the growth of bacterial spores.

Besides training of students to become prompt practitioners and dentist, it is also the purpose of curriculum designers to motivate and target the students as lifelong learners ${ }^{9}$.

Therefore, due to scant availability of local data on the subject, the rationale of the study was to assess the connection between dentists' qualification and adequacy of sterilization and infection control practices among dentists.

\section{METHODOLOGY}

This comparative cross-sectional study was conducted Liaquat College of Medicine and dentistry and Dar ul sehat hospital (LCMD) and Karachi Medical and dental College (KMDC) from January to June 2018. The study population was general dental practitioners and consultants working in LCMD and KMDC. The sample population of dental care professionals were interviewed by convenience sampling technique after taking their verbal consent. The inclusion criterion was general dental practitioners (graduates) and consultants (post graduates) from recognized dental colleges and institutes. The exclusion criteria were dental practitioners and consultants not given consent for the study. A predesigned questionnaire was used and GDPS and consultants were interviewed regarding personal protection cross infection control measures, instrument sterilization and operatory disinfection after taking informed verbal consent. Sample size of 89 GDPs and consultants was calculated using Rao soft software; using the prevalence as 115, response distribution of $50 \%$ margin of error as $5 \%$, and $95 \%$ confidence interval.

Data was entered and analyzed on SPSS version 13. Means and standard deviations were used to summarize continuous variables while percentages were used for categorical variables.

Chi Square Test was applied to find statistical significance between categorical variables. The continuous variables evaluated were age, gender, mean working experience and no. of practicing hours. Statistically significant $p$-value was $<0.05$.

\section{RESULTS}

The mean age of participants was $31.80 \pm 9.27$ years. The result shows the GDPs were $57.8 \%$ and consultants were $42.2 \%$ (Figure- I). Males were $46.7 \%$ and females were $53.93 \%$, (Figure - II). The practices

\section{FIGURE I: TYPE OF PRACTICE OF GDPS AND CONSULTANTS}

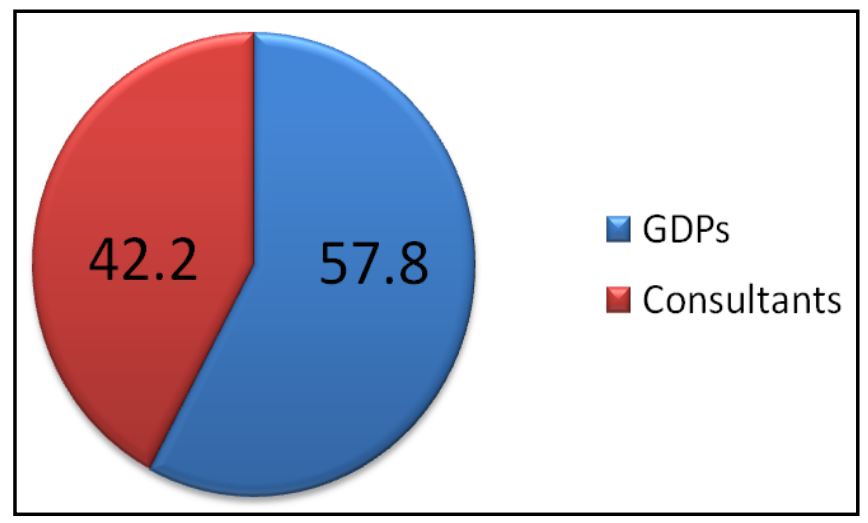

\section{FIGURE II: SHOWING GENDER DISTRIBUTION OF} PARTICIPANTS

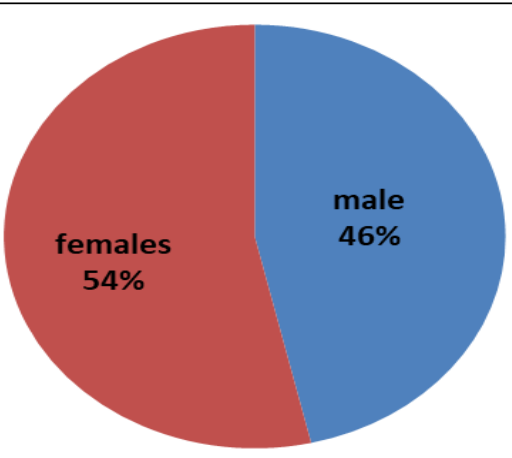

\section{FIGURE III: PRACTICES OF INFECTION CONTROL AMONG GDPS AND CONSULTANTS}

\section{PROTECTIVE BARRIERS}

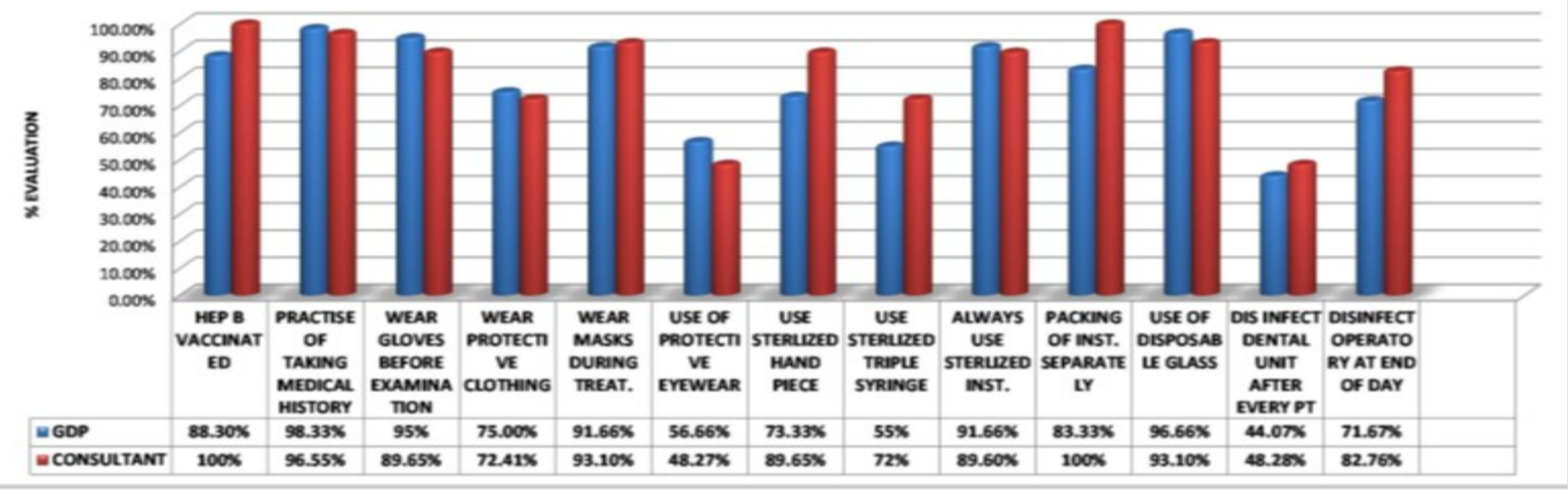


of dentist against Infection control were also assessed and evident in Figure III. Mean working experience was 7.80 years and the number of practicing hours per day was 6.20 hours per day.

Association between dentist's qualification (GDPS and consultants) and different methods of sterilization was evaluated which shows significant P-value i.e. $<0.05$. The variables with significant $P$-value were disinfecting operatory at the end of the day i.e. 0.013 (Figure IV) and biological spore test i.e. 0.0175.

\section{FIGURE IV: PERCENTAGE OF DISINFECTING THE OPERATORY AT THE END OF DAY}

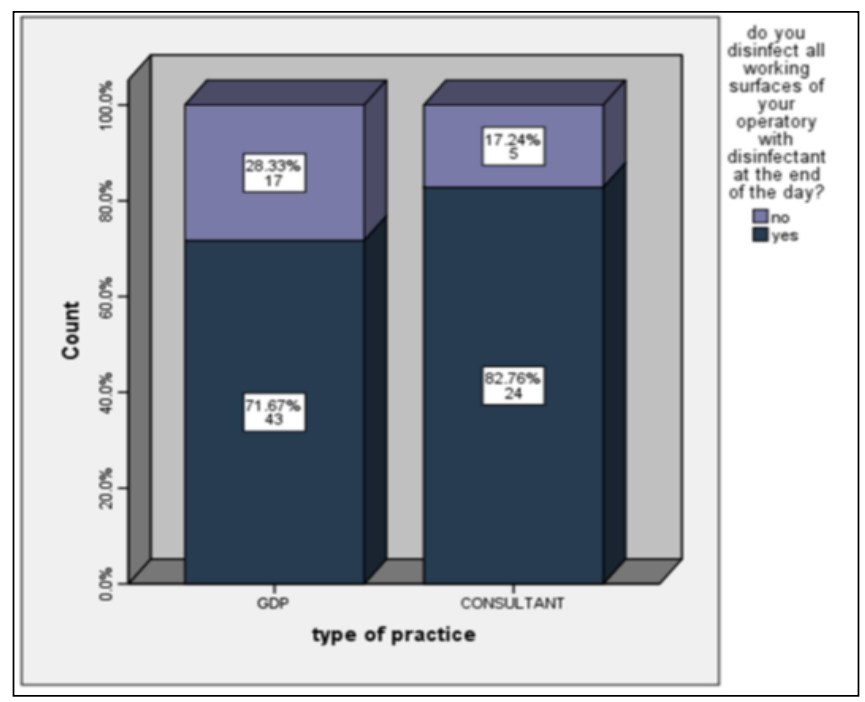

\section{DISCUSSION}

Dentistry chiefly engross not merely by patient to patient, but also by the dentist to patient or dental personnel to patients, dental laboratory to dental health care workers (DHCWs) and patients.

Sterilization and disinfection of dental equipments and clinics is of extreme significant to defend against lethal ailments like HIV, hepatitis, etc ${ }^{10}$.

This prospective, cross sectional study had shown that GDPs comprises of more fraction of practicing dental community in the Karachi city. The mean working experience of the practitioners serving the community was 7.8 years in our study which is quite enough to deal with normal dental complaints and procedures of the community. This is not in consistent with the study conducted 2012 which showed that $94 \%$ of their participants had working experience of $1-5$ years $^{11}$.

The participants were also asked for general practice of sterilization and disinfection.

Injury by contaminated instruments presents a major risk to dental team. They were asked for vaccination against hepatitis $B$, inquire about medical history prior to examination, wearing of gloves for every patient, use of sterilized hand piece, use of Disinfected triple syringe, use of sterilized instruments, packing of instruments separately within sterilized pouches and disinfection of dental unit after every patient. All the variables show no significant results which shows that the general practice towards sterilization methods was almost equal. These are in consistent with other studies which revealed healthy and efficient infection control practices of dentists ${ }^{11,12}$. In A study conducted at Dow university of Health Sciences in 2012 revealed that Majority of the dentist wore gloves whilst treating patients, $484(98.6 \%)$ of participants constantly changed their gloves after each patient while 11 $(2.2 \%)$ perform this occasionally ${ }^{13}$.

A research was performed amongst dental students of Dow International Dental College (DUHS) to discover their echelon of knowledge, attitude, and practice regarding infection control procedures. Significant differences among the study groups were observed for means of practice scores $(p \leq 0.01)$ and significant linear correlation was observed between knowledge and practice scores $(p \leq 0.01)$. Among knowledgeattitude and attitude-practice scores no differences were seen ${ }^{14}$.

Our study revealed that majority of the respondents were vaccinated for Hepatitis B. This is in consistent with the study conducted in Iran which revealed that approximately $96.7 \%$ of the participants were vaccinated against Hepatitis $\mathrm{B}^{15}$. This showed that majority of the health care workers were aware of the protocol of vaccination against Hepatitis B and possible health hazards which may occur after suffering from the disease.

In our study, the variable with significant $p$ value were disinfecting the operatory at the end of the day and biological sporing test. Disinfecting operatory at the end of the day is very important. Researchers have shown that the surroundings of the clinic have been contaminated by the air borne microbes after dental procedure especially surgical procedures. In a study conducted in UK in 2008 contamination of operatory and surfaces was evaluated by air borne microbes. Settle plates were used which identifies and quantifies the air borne microorganisms. Approximately 193 monotypes of distinct colonies which comprised of 73 species of microorganism were identified which is quite significant amount. The quantity of microbes was assessed during clinical activity and inactivity which revealed that mean number of different monotypes was 14.3 and 5 respectively ${ }^{16}$. Other studies also support this finding ${ }^{17}$.

As it has been evident that the consultants were more aware of the hazards of not disinfecting operatory at the end of the day as by doing this they prevent cross infection control for the next day patients and dental personnale. Leaving the operatory un-disinfected will encourage the growth of unwanted organisms and harmful bacterias which will cause cross infection among patients and staff members. In a study conducted Hyderabad in 2015 showed that $66.7 \%$ of the dentist $\mathrm{s}$ carried out disinfection methods for 
sterilization of the clinic area ${ }^{10}$.

The use of biological sporing test for the evaluation of sterilization is a novel method which should be regularly used to assess the quality of sterilization methods. It has been evident from the study that Consultants more frequently use biological sporing test and effectively monitors of sterilization. A study conducted in Iran which evaluated the role of use of indicators in a hospital since 1997 to 2011 and it revealed that they found profound difference regarding use of indictors since 1997 to 2011 in which hospital had achieved $100 \%$ use of chemical indicators although use of biological indicators is not very frequent i.e. $63.65 \%{ }^{18}$.

A study published in American Journal of Infection Control in 2015 revealed that only twenty-two percent of practitioners $(n=46)$ used biological indicators, and $17 \%(n=39)$ of the sterilizers reported positive results for bacterial growth. The identified cause of positive results were due to problem in the method (e.g. temperature, time, or pressure), an lack of supervision of the procedure done by the assistant, and unattended maintenance ${ }^{19}$.

Another study also highlighted the role of use of biological sporing test in dental practice ${ }^{20}$.

Limitations: Limitations of the study are that small sample size and recall bias.

\section{CONCLUSION}

It was concluded that the connection between dentist qualification and adequacy of sterilization in some aspects was significant, those having higher qualifications than simple graduates were doing daily and prompt sterilization.

Ethical permission: Liaquat College of Medicine \& Dentistry ERC No. EC/17/16, dated: 15-05-2016.

Conflict of Interest: There is no conflict of interest.

Funding: There was no any funding agency.

\section{REFERENCES}

1. Ashfaq MW, Chatha MR, Sohail A. Awareness of needlestick injuries among the dental health professionals at Lahore medical and dental college. Pak Oral Dental J. 2011; 31: 255-57.

2. Shah $\mathrm{AH}$, Wyne $\mathrm{AH}$. Cross-infection control in dentistry: A review. Pak Oral Dental J. 2010;30(1): 168-74.

3. Khan AS, Rahim A, Bangash TH, Chughtai MA, Mehmood Z. Infection control in dentistry knowledge and practices regarding barrier techniques, post exposure management and prophylaxis - A study. Pak Oral Dental J. 2009; 29(2): 235-40.

4. Mbaisi EM, Ng'ang'a Z, Wanzala P, Omolo J. Prevalence and factors associated with percutaneous injuries and splash exposures among health-care workers in a provincial hospital, Kenya, 2010. Pan Afr Med J. 2013; 14 : 10. doi: 10.11604/pamj.2013.14.10.1373.

5. Organization WH. The world health report 2002 Reducing risks, Promoting healthy life. World Health Organization. 2002. Available from: https:// www.who.int/ whr/2002/en/

6. Gupta A, Anand S, Sastry J, Krisagar A, Basavaraj A, Bhat SM, et al. High risk for occupational exposure to HIV and utilization of post-exposure prophylaxis in a teaching hospital in Pune, India. BMC Infect Dis. 2008; 8: 142. doi: 10.1186/1471-2334-8-142.

7. Shaghaghian S, Golkari A, Pardis S, Rezayi A. Occupational Exposure of Shiraz Dental Students to Patients' Blood and Body Fluid. J Dent (Shiraz). 2015; 16(3): 206-213.

8. Baig NN, Aleem SA. Occupational Hazards among Dental Surgeons in Karachi. J Coll Physicians Surg Pak. 2016; 26(4): 320-2. doi: 2300.

9. Ahmed SDH, Mubeen SM. Exploring teaching style in an undergraduate medical college following traditional curriculum in Pakistan. J Pak Med Assoc. 2013; 63(11): 1409-14.

10. Kumar A. Evaluation of sterilization at dental clinics in hyderabad city-a cross-sectional study. J Adv Med Dent Sci Res. 2015; 3(2): 38-41.

11. Siddiqui HK, Ikram K, Aftab NH, Uzair $F$. Knowledge and practice of sterilization among different health care workers. Pak Oral Dent J. 2014; 34(3): 507-9.

12. Mohiuddin S, Dawani N. Knowledge, Attitude and Practice of Infection Control Measures among Dental Practitioners in Public Setup of Karachi, Pakistan: Cross-Sectional Survey. J Dow Univ Health Sci. 2015; 9(1): 3-8.

13. Malik A, Shaukat MS, Qureshi A. Needle-Stick Injury: A Rising Bio-Hazard. J Ayub Med Coll Abbottabad. 2012; 24(3-4): 144-6.

14. Ali FM, Hussain A, Maqsood A. Knowledge, Attitude and Practice concerning infection control measures among dental health care providers of Dow University of Health Sciences. Pak Oral Dent J. 2014; 34(3): 452-56.

15. Hamissi J, Tabari ZA, Najafi $K$, Hamissi $H$, Hamissi Z. Knowledge, Attitudes and Practice of Hepatitis B vaccination among Iranian dentists. Int J Collaborat Res Intern Med Public Health. 2014; 6(7): 199-206.

16. Decraene V, Ready D, Pratten J, Wilson M. Air-borne microbial contamination of surfaces in a UK dental clinic. J Gen Appl Microbiol. 2008; 54 (4):195-203.

17. Luksamijarulkul $P$, Panya $N$, Sujirarat $D$, Thaweboon S. Microbial air quality and standard precaution practice in a hospital dental clinic. J Med Assoc Thai. 2009; 92(7): S148-S55.

18. Jabbari $H$, Alikhah $H$, Sahebkaram Alamdari $N$, 
Naghavi Behzad M, Mehrabi E, Borzui L, et al. Developing the use of quality indicators in sterilization practices. Iran J Public Health. 2012; 41(7): 64-9.

19. Patiño-Marín N, Martínez-Castañón GA, ZavalaAlonso NV, Medina-Solis CE, Torres-Mendez F, Cepeda-ArguellesO. Biologic monitoring and causes of failure in cycles of sterilization in dental care offices in Mexico. Am J Infect Control. 2015;
43(10): 1092-5. doi: 10.1016/j.ajic.2015.05.034.

20. Rani L, Pradeep. Sterilization Protocols in Dentistry - A Review. J Pharmaceutic Sci Res. 2016; 8(6): 558-64.

21. Kashif M, Khan MI, Iqbal N, Mazhar L, Mahrukh S, Arshad $M$, et al. Effectiveness of sterilization and disinfection of infected teeth for institutional use. Med Forum. 2015; 26(12): 7-10.

AUTHOR AFFILIATION:

Dr. Mehwash Kashif (Corresponding Author) Associate Professor, Department of Oral Pathology Karachi Medical and Dental College Karachi, Sindh-Pakistan.

Email: mehwashkashif@gmail.com

\section{Dr. Muhammad Abdullah Kamran}

Department of Orthodontics, Liaquat College of Medicine and Dentistry Dar-ul-Sehat Hospital, Karachi, Sindh-Pakistan.

\section{Dr. Tahera Ayub}

Associate Professor

Department of Oral and Maxillofacial Surgery Liaquat College of Medicine and Dentistry

Dar-ul-Sehat Hospital, Karachi, Sindh-Pakistan.

\section{Prof. Syed Sheeraz Hussain}

Department of Orthodontics

Karachi Medical and Dental College

Karachi, Sindh-Pakistan.

\section{Dr. Muhammad Irfan Khan}

Associate Professor, Department of Pathology Karachi Medical and Dental College

Karachi, Sindh-Pakistan. 